\title{
Coexistence of Occupational Asthma and Desquamative Interstitial Pneumonia: A Case Report
}

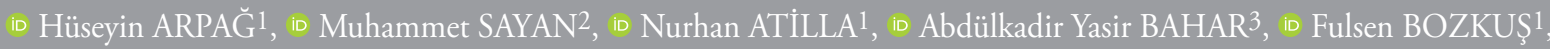 \\ iD Hasan KAHRAMAN', iD Mahmut TOKUR² \\ ${ }^{1}$ Kahramanmaraş Sütçü İmam University Faculty of Medicine, Department of Chest Diseases, Kahramanmaraş, Turkey \\ ${ }^{2}$ Kahramanmaraş Sütçü İmam University Faculty of Medicine, Department of Chest Surgery, Kahramanmaraş, Turkey \\ 3Kahramanmaraş Sütçü İmam University Faculty of Medicine, Department of Pathology, Kahramanmaraş, Turkey
}

\begin{abstract}
Desquamative interstitial pneumonia (DIP) is an interstitial pneumonia whichis characterised by diffuse intra alveolar accumulation of macrophages. Restrictive type of respiratory failure occurs in this entity. Although DIP is an idiopathic disorder, smoking is a major risk factor in etiology. In addition, occupational exposure can cause this pathology. The cornerstone of treatment of DIP is removing the state of exposure such as smoking or occupational exposure. Herein, we presented a case of coexistence of occupational asthma and DIP.
\end{abstract}

Keywords: Asthma, desquamative interstitial pneumonia, occupational exposure

\section{Introduction}

Desquamative interstitial pneumonia (DIP) was first described by Liebow et al. in 1965 (1). The etiology of DIP is unknown. While DIP is an idiopathic disorder it is thought to be associated with smoking habit. Pneumoconiosis, some rheumatologic disorders, viral infections and drug reaction can be accepted as etiologic factors in non-smoker individuals (2-4). DIP is generally seen in the age range of 40-60 years and it is seen more frequently in male patients (1-6). The diagnosis of DIP is not easy and usually lung resection is required. Histopathologically pigmented macrophages and sometimes giant cells collection are detected in distal airway (3).

\section{Case Report}

Thirty one-year-old welder, non-smoker, male patient admitted to us with dyspnea, cough and chest tightness complaints. His medical history included occupational asthma and use of inhaled bronchodilator therapy for 10 years. He was diagnosed as having occupational asthma due to his respiratory symptoms and positivity of reversibility test on pulmonary function tests occurred in 2 years after he started his welding job. Rhonchi and prolonged expirium were detected at the bilaterally lower zones on thorax auscultation. Despite using of inhaled bronchodilator therapy regularly his respiratory symptoms were not healed. Hyperinflation and linear density increase at right middle zone on chest X-ray. Thorax computed tomography revealed the nonhomogeneous infiltrates which featured ground glass densities distributed patchy peripheral (Figure 1). There was no restriction in pulmonary function tests. The diffusing capacity for carbon monoxide was $80 \%$. There was neither hypoxia nor hypercapnia on arterial blood gas analysis. His laboratory tests including hemogram, biochemical tests, collagen tissue diseases markers and urine tests were normal. Informed consent form included intervention and publishability of his medical records were obtained from the patient then fiberoptic bronchoscopy

Address for Correspondence: Muhammet SAYAN, Kahramanmaraş Sütçü İmam University Faculty of Medicine, Department of Chest Surgery, Kahramanmaraş, Turkey E-mail: drsayann@gmail.com ORCID ID: orcid.org/0000-0002-5402-9031

Cite this article as: Arpağ H, Sayan M, Atilla N, Bahar AY, Bozkuş F, Kahraman H, Tokur M. Coexistence of Occupational Asthma and Desquamative Interstitial Pneumonia: A Case Report. Bezmialem Science 2019;7(1):65-7. 
and transbronchial biopsy were performed but it was not for diagnostic purpose. Lung wedge resection was performed via video assisted thoracic surgery. Histopathologically; interstitial fibrosis and thickening, lymphocytic and plasmacytic infiltrates and accumulation of macrophages and giant cells were detected in alveolar lumen (Figure 2). Final pathology was reported as DIP based on that histopathologic signs. We administered methylprednisolone treatment $(1 \mathrm{mg} / \mathrm{kg})$ to patient with diagnosis of occupational asthma with DIP. After 6 months from steroid therapy, clinical and radiological improvement were achieved in patient and corticosteroid treatment was discontinued. The patient was followed without treatment. Here, we presented this rare association.

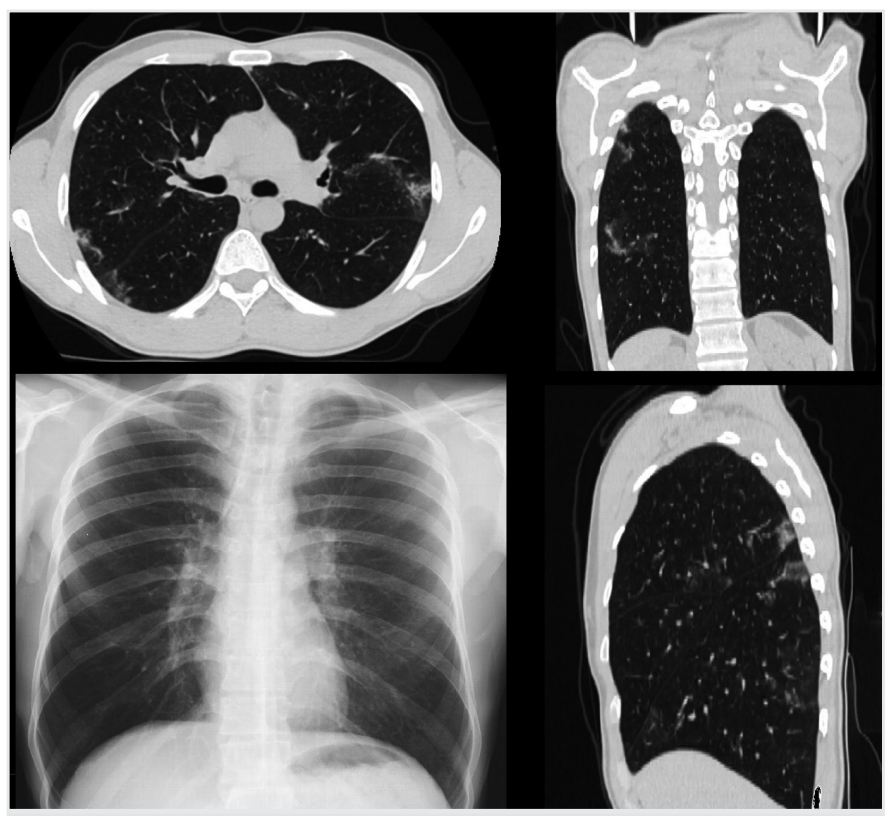

Figure 1. Radiologically; increase of pleuroparenchymal density, patchy ground glass located peripheral regions and increase of reticular density are seen in the bilateral lung fields

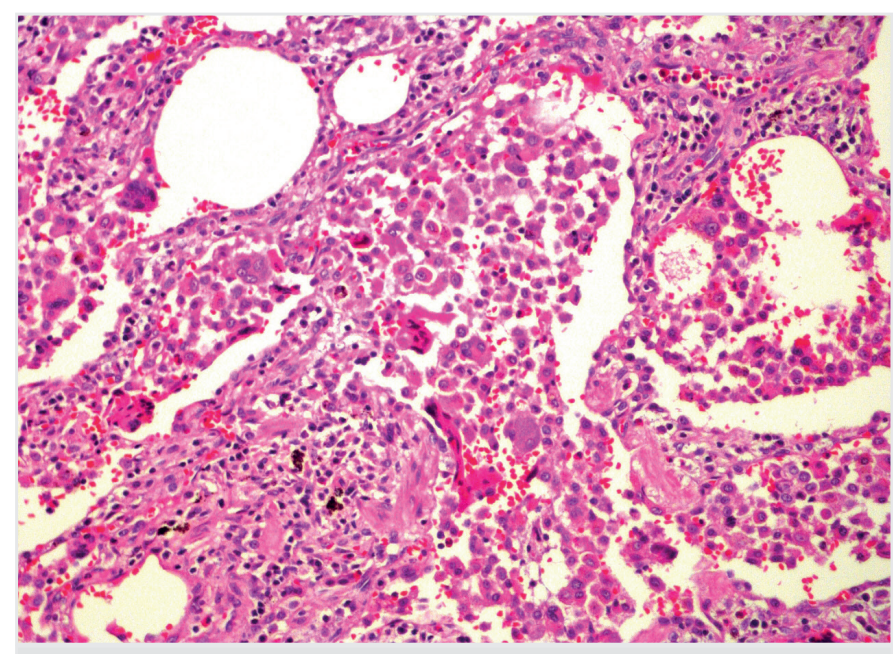

Figure 2. Large eosinophilic cytoplasmic alveolar macrophages and giant cells filling the alveoli are seen (hematoxylin and eosin, 200x magnification)

\section{Discussion}

DIP is a rare type of interstitial lung disease. DIP was first described by Liebow et al. (7) in 1965. DIP is a restrictive disorder. Radiologically it is characterised by diffuse infiltration. Histopathologically, intraalveolar diffuse macrophage accumulation is seen (7). Although etiology of DIP is unknown, usually it is detected in smoker individuals. Other accused factors in etiology of DIP are; environmental-occupational exposure, drug related reactions, viral infections, rheumatologic and autoimmune diseases, solder fumes, copper dust, fire extinguisher powder, diesel fumes, inhalation of nylon fibers and marijuana habit $(2,3,6)$. Our patient was non-smoker but he had been a welder for 10 years so we linked the cause of DIP of him to this condition. Usually DIP is seen in the middle age and male population (1). The age and gender of our patient (31-year-old and male) were also consistent with the literature.

Common symptoms of DIP are cough and shortness of breath. Our patient's complaints were cough, dyspnea and chest tightness. Inspiratory velcro rales and clubbing can be detected on physical examination in the cases of DIP (8). But endinspiratory rhonchi and prolonged expiration and no rales and no clubbing were found in our patient. We thought the cause of rhonchi was coexisting asthma. Radiologically, chest X-ray may be normal or increased reticular traces, ground glass patchy opacities may be detected on thorax computed tomography (CT) or high-resolution CT (9). Findings of thorax CT of our case was coherent with literature.

DIP can lead to restrictive type deterioration in pulmonary function tests $(2,7,10)$. But, pulmonary function tests of our patient showed obstructive pattern and there was no restriction. We linked this condition to the accompanying asthma.

Histopathologically, intra alveolar accumulation of pigmented macrophages and mild interstitial fibrosis are seen in DIP (6). Similarly interstitial fibrosis and thickening, lymphocytic and plasmacytic infiltrates and accumulation of intra alveolar macrophage and giant cells were detected in histopathologic examination of our patient. Removing the etiological factors such as smoking, occupational or environmental exposure, drug reaction etc. is the main factor of treatment of DIP. Additionally corticosteroid and even immunosuppressive treatments may be needed in some patients $(5,7,10)$. We recommended to him change his welding job and started to corticosteroid treatment. Almost complete clinical and radiological recovery was achieved in our patient for 6 months.

Consequently, we reported here that DIP due to occupational exposure may occur in non-smoker individuals and occupational asthma may accompany to this entity.

\section{Ethics}

Informed Consent: It was obtained.

Peer-review: Externally peer-reviewed. 


\section{Authorship Contributions}

Surgical and Medical Practices: H.A., M.S., M.T., Concept: M.S., M.T., A.Y.B., Design: H.A., M.S., N.A., A.Y.B., Data Collection Or Processing: H.A., M.S., N.A., A.Y.B., M.T., Analysis Or Interpretation: H.A., M.S., N.A., A.Y.B., F.B., H.K., M.T., Literature Search: H.A., M.S., N.A., A.Y.B., F.B., H.K., M.T., Writing: H.A., M.S.

Conflict of Interest: No conflict of interest was declared by the authors.

Financial Disclosure: The authors declared that this study received no financial support.

\section{References}

1. Aubry MC, Wright JL, Myers JL. The pathology of smoking-related lungdisease. Clin Chest Med 2000;21:11-35.

2. Tubbs RR, Benjamin SP, Reich NE, McCormack LJ, Van Ordstrand HS. Desquamative İnterstitial pneumonitis. Cellular phase of fibrosing alveolitis. Chest 1977;72:159-65.

3. Godbert B, Wissler MP, Vignaud JM. Desquamative interstitial pneumonia: an analytic review with an emphasis on aetiology. Eur Respir Rev 2013;22:117-23.
4. Moon J, DuBois RM, Colby TV, Hansell DM, Nicholson AG. Clinical significance of respiratory bronchiolitis on open lung biopsy and its relationship to smoking-related interstitial lung disease. Thorax 1999;54:1009-14.

5. Kawabata Y, Takemura T, Hebisawa A, Sugita Y, Ogura T, Nagai S, et al. Desquamative interstitial pneumonia may progress to lung fibrosis as characterized radiologically. Respirology 2012;17:1214-21.

6. Craig PJ, Wells AU, Doffman S, Rassl D, Colby TV, Hansell DM, et al. Desquamative interstitial pneumonia, respiratory bronchiolitis and their relationship to smoking. Histopathology 2004;45:275-82.

7. Liebow AA, Steer A, Billingsley JG. Desquamative interstitial pneumonia. Am J Med 1965;39:369-404.

8. Selman M. The spectrum of smoking-related interstitial lung disorders: then ever-ending story of smoke and disease. Chest 2003;124:1185-7.

9. Attili AK, Kazerooni EA, Gross BH, Flaherty KR, Myers JL, Martinez FJ. Smoking-related interstitial lung disease: radiologic clinical pathologic correlation. Radio Graphics 2008;28:1383-96.

10. Yousem SA, Colby TV, Gaensler EA. Respiratory bronchiolitis associated interstitial lung disease and its relationship to desquamative interstitial pneumonia. Mayo Clin Proc 1989;64:1373-80. 